\title{
The Impact of COVID-19 on the International Education Market in China
}

\author{
${ }^{1}$ Fuzhou No.1 High School, 350000, Fuzhou, Fujian, China \\ ${ }^{2}$ Qinyang No.1 High School, 454550, Jiaozuo, Henan, China \\ *Corresponding author. Email: guanghua.ren@gecacademy.cn \\ These authors contributed equally.
}

Linrui $\mathrm{Hu}^{1, *}{ }^{*} \dagger$ Yuze Zhang ${ }^{2, \dagger}$

\begin{abstract}
COVID -19 pandemic has an extreme effect on the international education and Chinese students' studying abroad plan. Under this circumstance, this study aims at researching the present situation of the international education market and the changing choice of Chinese international students under the impact of the COVID-19 pandemic in 2020. This article first discusses the impact of the pandemic on the international education market, the distinct percentage of international students in a different city, the differences of international students in distinct countries, the change in Chinese students' studying abroad plan, the negative, increasing speed of income in the international education examination and consultation field, and the impact of the pandemic on the Chinese students studying abroad plan. Then, it argues that with the change of policy of many countries for international students and the financial problems, international students have become more unnecessary to residents and countries. All those facts and events cause a result that there are fewer and fewer students who liked to study abroad in 2020. Because of the condition in the whole of market, the trend of studying abroad transfers to another way that accomplice for the traditional educational system and the cost of international students is also decreasing significantly. Besides, the COVID-19 pandemic absolutely influences international education, and we must relocate the whole international education market.
\end{abstract}

Keywords: COVID-19, international education, China.

\section{INTRODUCTION}

\subsection{Background.}

The COVID-19 outbreak in 2020 has influenced international education and students studying abroad all over the world. For the students who have studied abroad in foreign countries for a while, many of them are not allowed to continue to study abroad and come back to their own countries since most of the universities are closed. Hence students can only study at home, using computers, and attend online courses. What is more, for the students who are planning to study abroad, many of them begin to reconsider their international education plan because there are many policies and difficulties for Chinese students to consider. First, the underline TOEFL and IELT exams are cancelled, which contribute to the inaccessibility to the language certification that is crucial for students to apply for most universities in the world. Second, the international airlines from China to foreign countries are cancelled to cut off the transmission routes and decrease the number of infected people. Third, many countries have published policies to ban foreign people from getting access to their countries, and some countries even have some cities blocked to reduce the spread of the disease. Finally, the medical resources are in shortage, and vaccines are still under examination and experiment, which means people will continue to be exposed to the danger of getting infected. Therefore, it is apparent that the market of international education and the plan of Chinese international students will definitely be affected, which strongly arouse the interest of researchers and lead to the accomplishment of investigations and this essay related to the present situation of international students in China.

China has become the biggest international student exporting country. From 1978 to 2014, the total number 
of Chinese international students had reached 351.84 million. In 2016, China had 54.5 million Chinese international students, which increased by $36.2 \%$ compared to the number in 2012. Also, China had established a close relationship of education communication and cooperation with more than 180 countries and 46 important international organizations. China not only makes great contributions to the world education industry but brings about enormous economic effects.

This study mainly presents the impact of the pandemic on the international education market, the Chinese students studying abroad plan the increasing difficulty of studying abroad, and the urgent need to relocate the whole international education market, generally discussing the international market during and after the COVID-19 pandemic.

\subsection{Related research}

\subsubsection{The limit and restriction in mobility of international students}

Xiong et al. did research on how students in Mainland China and Hong Kong conceive overseas studies plans against the COVID-19 crisis, using the method of distributing the questionnaires via online survey systems (Qualtrics and Wenjuanxing) to the above two groups of students, which led to a conclusion that the pandemic has not only significantly decreased international student mobility but is also shifting the mobility flow of international students. The research team also found that the global health crisis would intensify social and economic inequalities across higher education systems [1]. Mok et al. have studied the affection of pandemic of COVID-19 for mobility and perspective of international students, adopting a method that investment a bunch of different the information of survey and statistic such as Institute of International Education and many other surveys to support detail numbers and data to the report and the essay. At the conclusion of the essay, the mobility of international students has decreased significantly by the stricter restriction for international travel and pandemic of COVID-19 produced a profound affection on the higher education and aroused the concern of students about safety and health of themselves, especially international students [2]. Hamada et al. learn that under the dynamic of COVID-19 how to solve the problem of transmission of students without centralized policy [3]. Mamada uses the method of adopting the daily mobility data from Teralytics (Zürich, Switzerland) from Jan 1 to April 20, and $30 \%-63 \%$ think that the condition of transmission agrees with the condition baking to normal. The final finding is that the best way to control COVID-19 is to stay at home and keep social conditions with each other [4].

\subsubsection{The self-recognition of international students}

Firang explored the impact of the pandemic on international students in Canada, using the method of gathering statistics, referring to previous research, and doing questionnaires, which led to a conclusion that international students are more vulnerable due to their immigration status during this pandemic period. The macro practitioners can address systemic and institutional issues that impact international students' well-being during the current global health crisis [5]. Kulyar explored the panic and influencing factors on international students, using a questionnaire filled out independently from the participants of several places in Hubei, especially in Wuhan, through official WeChat groups developed by the universities for international students, which led to a conclusion that many of the international students were afraid during the pandemic, which may be due to the fact that the respondents in affected areas paid more attention to the safety of their families his and may be associated with the respondent's age and their marital status [6]. Amerson et al. studied how to prove the health ability of international students is limited in the local place and how to affect them. Amerson uses the method that directly collects the information from students in the university from other countries and others. The result from the essay of Amerson announces that all the students in the future probably own the ability about health and related field [7].

\subsubsection{The opinion of students treats to different institutions in society}

Aristovnik researched the factor that significantly affects the lives of students in the world and the perspective of the higher education students for the future through the method based on the questionnaire distributed by the European Students' Union Survey and targeted higher education students. The final conclusion of the study is that the hospital and the universities present positive. Still, the bank and the government are not expected by the students. The vital factors deciding the perspective for the students' lives are the social position, mental and financial condition, gender, and stuff about the circumstance of students. In addition, this institution during pandemic time shows that they need financial subsidies from the government [8].

\subsubsection{The effect of the pandemic on the economy and educational system worldwide}

Matt research about the condition in the society about universities that the whole country sacrifice the business and financial condition to reduce the infect and spread of the disease, the COVID-19, or which kind of future or policy should be used. They are adopting the 
method based on the data and statistics from the society to predict and conclude to form the essay. The final result shows that for the US condition, the government should adopt a way that recovers the financial development and regain the normal condition in society, including the schools [9]. Kanwar and Carr outlines the implications of the COVID-19 crisis for international higher education and presents potential opportunities for governments and higher education institutions to refresh and redefine their approaches for the new normal, using the method of gathering statistics, referring to previous research, and quoting others' s opinion, which led to a conclusion that the COVID-19 pandemic presents an opportunity for governments and HEIs to develop and fast-track the adoption of disruptive models of international education that offer creative and sustainable solutions for the post-pandemic world Samifanni analyses the current situation in the Japanese education system and look for possible solutions to the problem of Internationalization without international travel, utilizing the Data Mining method and desktop study about the relevant data on COVID-19 pandemic and pertinent information about the Japanese education in relation to the present article, which led to a conclusion that the pandemic put a halt to internationalism and one way for the government of creating impact is to show attractiveness despite the lockdowns and blockages of internationalism [10].

\section{THE IMPACT OF THE PANDEMIC ON THE INTERNATIONAL EDUCATION MARKET}

\subsection{The percentage of international students in a different city has distinctions}

The level of the city has a great impact on the plan of Chinese students studying abroad during the epidemic in 2020. In the first level city, $42.9 \%$ of students delay the plan, $35.7 \%$ change their destination, and $21.4 \%$ cancel the plan. In the second-level city, $69.2 \%$ of students delay the plan, $15.4 \%$ cancel the plan, and $15.4 \%$ change the destination. In the third or fourth level city, $57.1 \%$ of students change the destination, $28.6 \%$ cancel the plan, and $14.3 \%$ delay the plan. The statistics indicate that students in different level cities have different decisions on their studying abroad plans. In the second-level city, the percentage of students who want to delay their plan is much higher. However, in the second level city, this number is really low. For the students who want to change their destination, the third or fourth level cities have a larger percentage, while in the second level, this number is the lowest. Also, more students choose to cancel their plan in the third or fourth level city than in the other two levels cities. So we can conclude that the level of cities may impact the students' studying abroad plan, which may be due to the development of the city and the education the students receive.

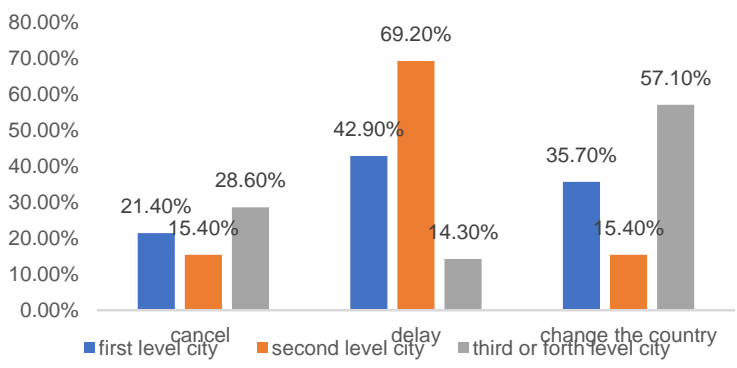

Figure 1 The impact of the epidemic on Chinese students studying abroad plan.

\subsection{The differences of international students in distinct countries}

In 2020, the intention of Chinese students to study in the TOP10 countries and regions also changed dramatically because of the pandemic. According to the graph, $23.8 \%$ of students want to go to the UK ranking the first, $22.1 \%$ of students intend to go to the USA ranking the second, and $21.3 \%$ of students prefer to go to Canada ranking the third. Then is Germany, whose number is $18.9 \%$, Japan, whose number is $18.9 \%$, Singapore, whose number is $15.6 \%$. The last three are Korean, whose number is $13.1 \%$, HK, China, whose number is $12.3 \%$, and Russian, whose number is $9.8 \%$. Surprisingly, more people would like to go to the UK rather than the USA, which may be due to the badly controlled pandemic in America and the slightly turbulent political situation.

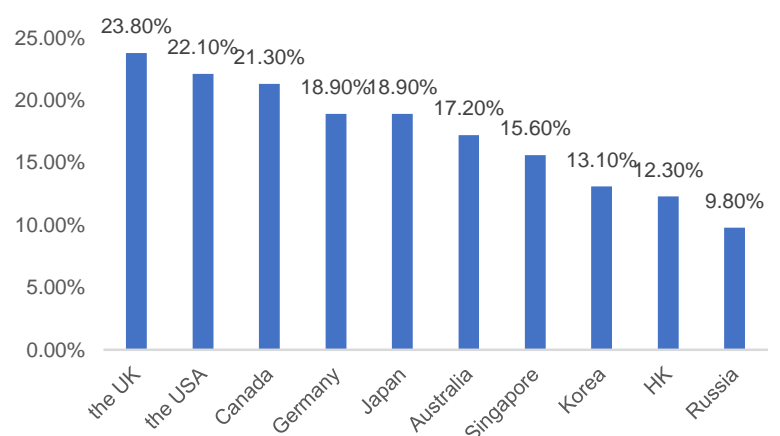

Figure 2 Chinese students intended to study in TOP 10 countries and regions in 2020

What is more, the increasing speed of the number of international students was negative $1.8 \%$. It was the first time for America to have the negative, increasing speed of the number of international students in the past ten years, after the speed of international students has been decreasing since 2015, which suggests that many international students are discouraged from studying in America in 2020 because of pandemic happened not only in the USA but in China. All of these numbers indicate that the pandemic influenced the countries in 
which the international students intended to study in 2020.

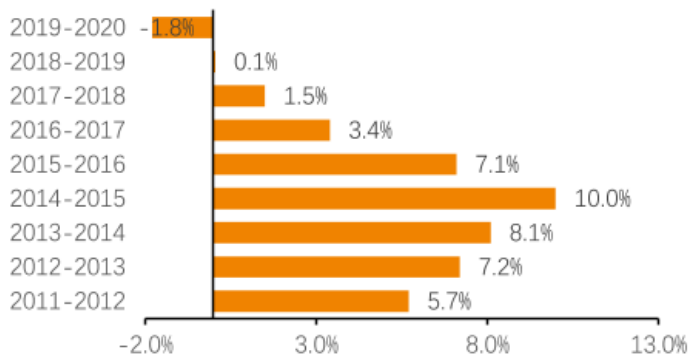

Figure 3 Increasing speed of Chinese students in the USA

\subsection{The change in Chinese students' studying abroad plan}

The attitude of international students about whether to study abroad is affected strongly by the pandemic in 2020. According to How Covid-19 Is Impacting Prospective International Students Across The Globe, published by QS, more than half of the international students from all over the world were influenced by the pandemic, and among them, the number of Chinese international students who are affected ranks first, which is $66 \%$. However, among these $66 \%$ Chinese students, $48 \%$ prefer to delay entry until next year, and only $4 \%$ of international students no longer want to study abroad.
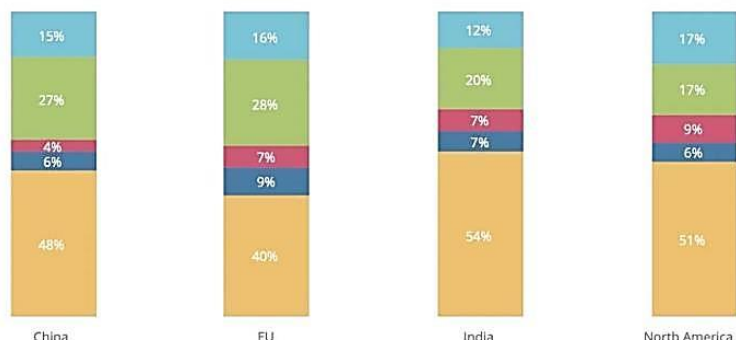

EI now intend to defer/delay my entry until next year -1 now no longer want to study overseas

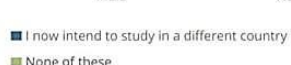
m None of these

Figure 4 The percentage of students who have different plans in each country

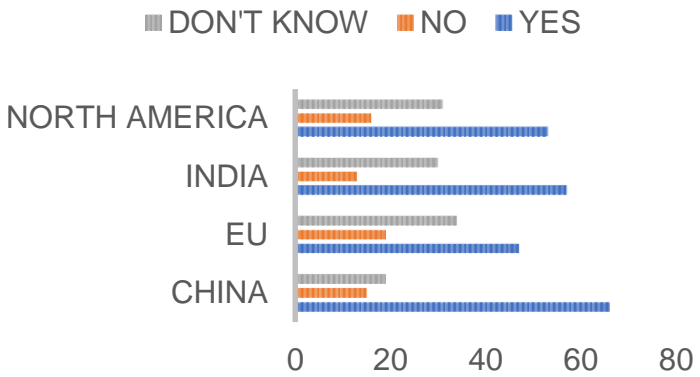

Figure 5 The percentage of students whose plans are affected by the pandemic in each country. Also, the chart suggests that for people who believe China was safer in $2020,55.2 \%$ intend to delay their plan, $24.1 \%$ prefer to change the destination, and $20.7 \%$ tend to cancel the plan.

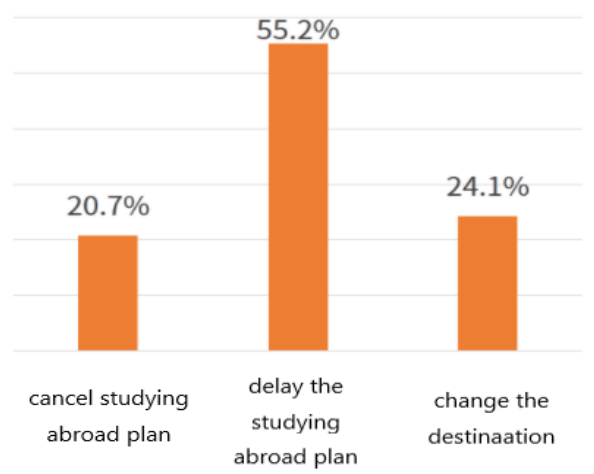

Figure 6 Attitudes of people who believe that China is safer towards overseas study plan in 2020 .

The year that the international students plan to study abroad also changed when the time passed in 2020 . From May to November, the number of students who want to study abroad in 2020 has been continued decreasing from $43 \%$ to $0 \%$. Instead, the number of students who want to study abroad in 2021 or even later has increased.

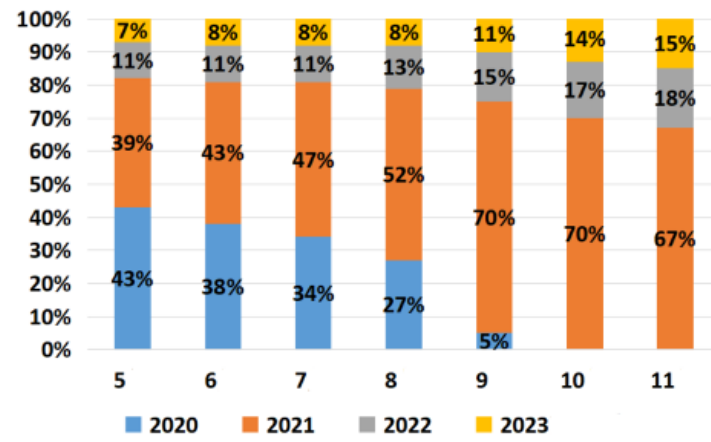

Figure 7 The choice of time for Chinese students to study abroad in different months

All these numbers indicate that although the pandemic affected international education, most students did not give up studying abroad. From my perspective, this phenomenon may attribute to the higher-quality education in some foreign countries and the profound impact of better education on one's career and future life. To conclude, although some international students cancel the plan, most students insist on their studying abroad plan, and the market for studying abroad is still considerable.

\subsection{The negative increasing speed of income in the international education examination and consultation field}

The income of international education experienced an obvious decrease during the pandemic. Before the third season,2020, the increasing speed of income was above $0 \%$. Yet since then, the increasing speed 
decreased and finally became negative $52.0 \%$ in the fourth season. In conclusion, the pandemic impacted international education enterprises. Still, the income in the field of international education will be more likely to increase after the pandemic since the international education market is still high potential and strongly optimistic.

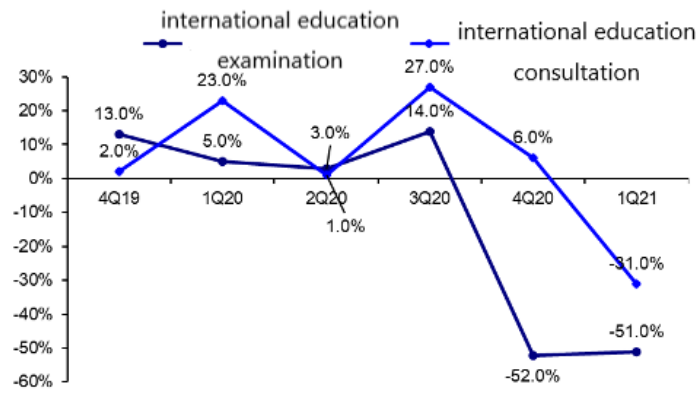

Figure 8 The apparent decrease in income in the international education field.

\section{THE IMPACT OF PANDEMIC ON THE CHINESE STUDENTS STUDYING ABROAD PLAN}

Several reasons have an impact on the studying abroad plan of international students. According to the chart, about $44 \%$ of people consider whether the university will open the underline courses, $40 \%$ people consider the vaccine, $36 \%$ people care about the number of the definite local cases, $27 \%$ people are concern with the legality of studying abroad and $24 \%$ people thought of the limitation of social distance. Also, in the essay Psychosocial impact of COVID-19 outbreak on international students living in Hubei province, China, written by Kulyar, M. F.-E.-A. Bhutta, Z. A. Shabbir, S. \& Akhtar, M. (2020), it is essential for the international students in affected areas to pay more attention to the safety of their families and the student's age their marital status. In conclusion, despite some traditional considerations about international study, most of the reasons are associated with the pandemic and the safety of international studies.

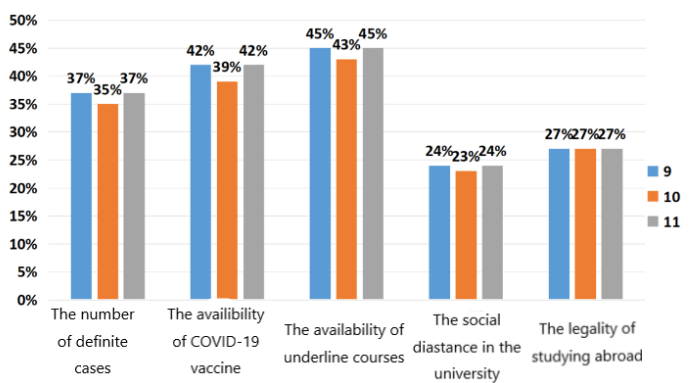

Figure 9 The biggest impact of the pandemic on the Chinese students studying abroad plan

\section{THE INCREASING DIFFICULTY OF STUDY ABROAD BY COVID-19}

With the change of policy of many countries for international students and the financial problems, international students have become unnecessary to residents and countries. All those facts and events cause a result that there are fewer and fewer students who like to study abroad.

For a long time, U.S has had the biggest market of international students, which means people studying affection and change in international students' market easier research the circumstance of international students market by analysing the market of U.S. Such as that, about 1.1 million international students were enrolled in U.S. institutions in the school year (SY) 2019-20, while there is only half of the number of students enrolling in the U.S. shows the whole of the market and every country added restriction in part block the spreading and infection of the COVID-19. More specifically, closures and limited access to U.S. embassies and consulates, travel restrictions, and personal safety considerations have complicated international students' visa issuance and travel plans. These rules or restrictions pulse an opponent force for international students to maintain an idea taking school abroad like the U.S. In the second place, the government of the countries tight the restriction in policy on the part of international students and residence holds a negative and hostile threat to international students, especially for Chinese students even all Asian students. Furthermore, the condition in the international, the domestic atmosphere even resist studying abroad and the students learning in other countries, and those of people or media likely to spread and publish a lot of extraordinary news to describe, slander other countries. The reason is that they want to raise public attention and attract a number of followers. The negative publicity causes a result on one hand that more and more people do not think study abroad is a good choice and studying abroad almost become a kind of a shame, on the other hand during the dynamic of COVID-19 most of the family have been injured in the economy since a bunch of company bankrupt in epidemic and people lose their job so that students study broad have to back to their own country without enough support of financial. The Weekly Economic Index (WEI) is an index of 10 weekly indicators of real economic activity, scaled to have the units of four-quarter percent change of real GDP. This index can show what happens in most of the families in their financial condition perfectly. In 2007, there are still 144000 international students. In 2012, there is a significant rise in the number of students study abroad. The turning point in 2019, after the climax of 2018, the number of international students appear of negative growth, and at this point, the COVID-19 start to spread in several countries and was steadily more serious. Until 
the move to 2021, the number of people who study abroad plunges suddenly, proving that international and domestic conditions are vital negative for students.

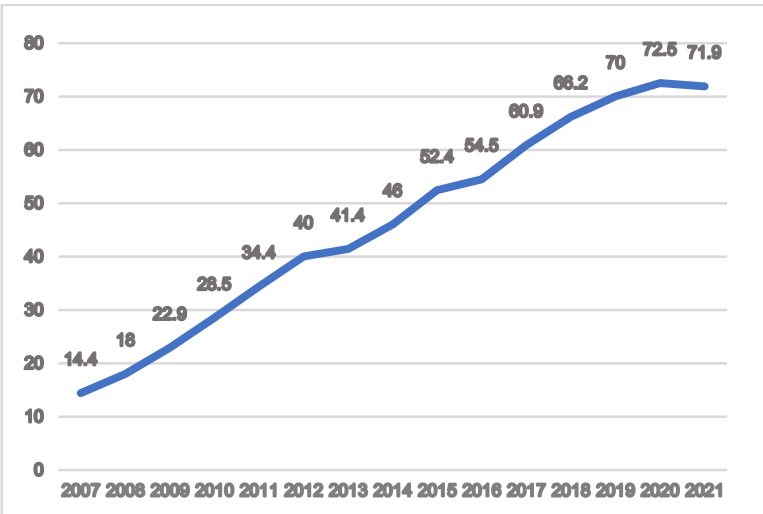

Figure 10 The Student's Number of Study Broad

\section{RESET THE WHOLE OF THE MARKET OF STUDYING ABROAD AND ITSELF}

Since the condition in the whole market, studying abroad transfers to another way that accomplices the traditional educational system. The cost of international students is also decreasing significantly. Therefore, the market of this part shows that this industry is still unstable to do.

The market for studying abroad has been changed totally compare with 15 years ago. At the time, the rare international students are one of the most valuable resources for the whole of the country because they can support unique information in many different ways such as capital construction, research in rockets, and stuff. Nonetheless, the condition right now becomes crucial different, with more and more people decided to study in other countries, the quality of international students is use, some of them still capable of becoming the main force to develop and build the country, others might are waste their own time to get a diploma only. Therefore, owing to the development of the domestic education system, studying abroad is not the only way to get a better future life. Instead, studying in own country may be proper for many people.

The potential international students are also different currently, in other words, the possible students who will likely study abroad have only two choices, one of it is the children of rich people; another is top great students in the school and supported by the government to study in other country and donate their force for the building of country backing to China after graduating. However, nowadays, most of the middle class have the ability to se their child to other countries.

In addition, those facts, the most important is the treat of country or government to international students, due to the accomplishment of the higher level of education system government tend to stop encouraging more students to study abroad but try to save students stay domestic to help construction and promote the higher education system. From the time that accomplishment of exam-oriented education in China, the government clear there are two significantly different methods of acquiring education, and one of it is study domestic, which is also most popular or receiving. Another has a less market at the beginning of the time. Nonetheless, it accepts by more and more people in China, causing the losses of domestic higher education students or graduation to make the government realize that this has become a vital question.

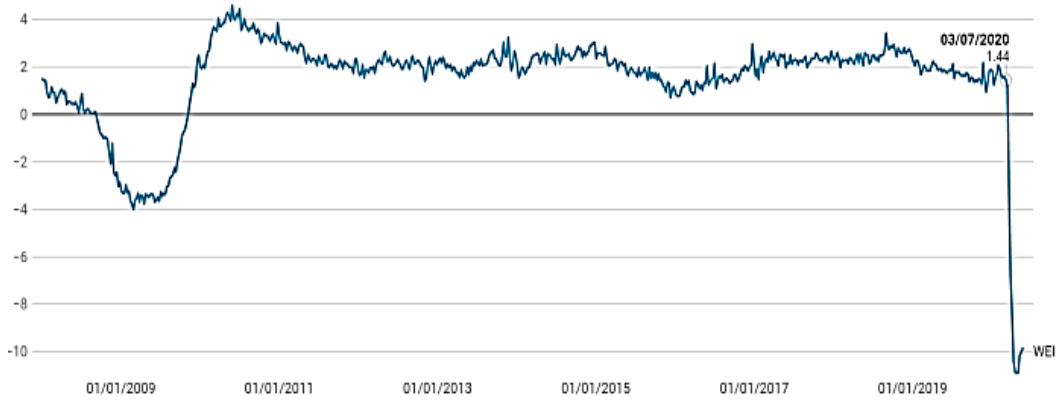

Figure 11 Weekly Economic Index

\section{CONCLUSION}

In conclusion, this study discusses the impact of COVID-19 on the international education market and overseas students studying abroad plan, indicating that the pandemic definitely causes many students' studying abroad plan to change and the income of the whole international market to decrease. Also, many countries, such as the USA, have carried on some policies to reduce the number of international students. Hence, it is more difficult for Chinese students to study abroad. Moreover, the vaccine of the COVID-19 is still under development and examination, which reveals that the safety of international students cannot be ensured. It seems that the future of the international market has such a gloomy picture, but actually, as the majority of students insist they're studying abroad plan, the trend of international education will remain. The boom of the economy in the international education field will come back. 


\section{REFERENCES}

[1] Jazieh, A. R., Coutinho, A. K., Bensalem, A. A., Alsharm, A. A., Errihani, H., Mula-Hussain, L., ... Guzman, R. B. D. (2021). Impact of the COVID-19 Pandemic on Oncologists: Results of an International Study. JCO Global Oncology, 7(7), 242-252.

[2] Firang, D. (2020). The impact of COVID-19 pandemic on international students in Canada. International Social Work, 63(6), 820-824.

[3] Kulyar, M. F.-E.-A., Bhutta, Z. A., Shabbir, S., \& Akhtar, M. (2020). Psychosocial impact of COVID-19 outbreak on international students living in Hubei province, China. Travel Medicine and Infectious Disease, 37, 101712.

[4] Kanwar, A., \& Carr, A. (2020). The impact of COVID-19 on international higher education: New models for the new normal. Journal of Learning for Development, 7(3), 326-333.

[5] Samifanni, F. (2020). Japan's International Education during COVID-19 Pandemic: Show Impact or Face Swift Death. Asian Journal of Humanities and Social Studies, 8(4).

[6] Mok, K. H., Xiong, W., Ke, G., \& Cheung, J. O. W. (2021). Impact of COVID-19 pandemic on international higher education and student mobility: Student perspectives from mainland China and Hong Kong. International Journal of Educational Research, 105, 101718.

[7] Aristovnik, A., Keržič, D., Ravšelj, D., Tomaževič, N., \& Umek, L. (2020). Impacts of the COVID-19 Pandemic on Life of Higher Education Students: A Global Perspective. Sustainability, 12(20), 8438.

[8] Howard, M. C. (2021). Who wants to reopen the economy during the COVID-19 pandemic? The daring and uncaring. Personality and Individual Differences, 168(168), 110335.

[9] Amerson, R. (2021). Striving to Meet Global Health Competencies Without Study Abroad. Journal of Transcultural Nursing, 32(2).

[10] Badr, Hamada S., et al. "Association between Mobility Patterns and COVID-19 Transmission in the USA: A Mathematical Modelling Study." Lancet Infectious Diseases, vol. 20, no. 11, 2020, pp. 1247-1254. 